\title{
Ensinar a ler em diferentes áreas do conhecimento: o que pensam os professores sobre o ensino da compreensão leitora?
}

\section{Enseñar a leer en diferentes áreas de conocimiento: ćlo que piensan el profesorado acerca de la enseñanza de la comprensión lectora?}

https://doi.org/10.34112/2317-0972a2019v37n77p129-143

\author{
PÂMELA Lopes Vicari ${ }^{\mathrm{I}}$ \\ Dayene Borges Guarienti ${ }^{2}$ \\ KÁRI LÚCIA ForNeCK ${ }^{3}$ \\ Silvana Neumann Martins ${ }^{4}$
}

Resumo: Apresentamos uma discussão a respeito de como alguns professores pensam e ensinam a compreensão leitora em sala de aula. A partir de um questionário, as respostas foram agrupadas em temáticas de análise, a partir das quais observamos que: a) a leitura é trabalhada na escola, na maior parte das vezes, com objetivo de desenvolver a fruição nos alunos, com menor preocupação na aprendizagem da compreensão leitora; e b) a visão dos entrevistados a respeito da inferência ainda não é clara, uma vez que não evidenciamos conhecimentos acerca das particularidades do ensino de estratégias de leitura. Por fim, fica evidente que há uma lacuna a ser preenchida no âmbito da formação inicial e continuada de professores, uma vez que verificamos que, ainda que se preocupem com a qualificação dos processos de leitura de seus alunos, não há muita clareza em como efetivamente devem ensinar seus alunos a compreender o que leem.

Palavras-chave: Ensino; leitura; formação docente.

RESUMEN: Se presenta una discusión acerca de cómo algunos profesores piensan y enseñan la comprensión lectora en el aula. A partir de un cuestionario, las respuestas fueron

1. Universidade do Vale do Taquari - UNIVATES, Lajeado, RS, Brasil.

2. Universidade do Vale do Taquari - UNIVATES, Lajeado, RS, Brasil.

3. Universidade do Vale do Taquari - UNIVATES, Lajeado, RS, Brasil.

4. Universidade do Vale do Taquari - UNIVATES, Lajeado, RS, Brasil. 
Ensinar a ler em diferentes áreas do conhecimento: o que pensam os professores...

agrupadas en temáticas de análisis, a partir de las cuales observamos que: a) la lectura es trabajada en la escuela, en la mayoría de las veces, con el objetivo de desarrollar la fruición en los alumnos, con menor preocupación en el aprendizaje de la comprensión lector; y b) la visión de los entrevistados acerca de la inferencia aún no es clara, ya que no evidenciamos conocimientos acerca de las particularidades de la enseñanza de estrategias de lectura. Por último, es evidente que hay una laguna a ser llenada en el marco de la formación inicial y continuada de profesores, ya que verificamos que, aunque se preocupan por la calificación de los procesos de lectura de sus alumnos, no hay mucha claridad en cómo efectivamente deben enseñar a sus alumnos a comprender lo que leen.

PALABRAS LlaVe: Enseñanza; lectura; formación docente.

\section{INTRODUÇão}

O discurso emergente no atual contexto educacional brasileiro tem problematizado a aprendizagem da leitura e os hábitos leitores dos estudantes brasileiros, ou, pelo menos, a possível falta deles.

$\mathrm{O}$ ensino da leitura preconizado por algumas escolas, e como o temos percebido, é o do ler por prazer, isto é, uma leitura baseada no princípio de que o aluno encontre prazer no ato de ler. Esse pensamento não é equivocado e nem deve ser desprezado, porém, em nosso entender, fundamentado pelos estudos psicolinguísticos, o ensino da leitura que perpassa a construção de um processo baseado unicamente na fruição não desenvolve por si só as habilidades de leitura necessárias para a inserção social dos indivíduos. Ler é também uma forma de adquirir conhecimento, ampliar vocabulário, interagir socialmente e produzir aprendizagens. Mas, para alcançar a compreensão do texto, é preciso reconhecer que o processo de leitura requer domínio de habilidades em diversos níveis cognitivos e metacognitivos, que não dependem exclusivamente de gostar ou não gostar de ler.

Mesmo a partir de estudos que possibilitam aprender sobre o ensino da leitura, os quais mencionamos no aporte teórico deste texto, ainda vemos relatos de práticas de ensino como o citado por Ferrarezi Jr. e Carvalho (2017, p. 34), em que a abordagem pedagógica consistiu em levar um livro ou qualquer outro texto para a sala sob a instrução "leiam, vou explicar o que ele significa e façam uma redação sobre o que acharam do texto". Isto é, ainda que se compreenda a importância da leitura na escola, as práticas de ensino não têm se mostrado potencializadoras do desenvolvimento de habilidades e estratégias que conduzam o aluno à compreensão do texto, 
o que fica evidente, inclusive, nos resultados das provas que avaliam o desempenho dos estudantes brasileiros como a Prova Pisa e a Prova Brasil.

Nesse sentido, ressaltamos que nossa motivação é oportunizar aos estudantes um ensino que os auxilie a resolver, de forma autônoma, os problemas enfrentados quando não ocorre a compreensão. Em outras palavras, desejamos que o aluno, quando em situações mais complexas, diante das dificuldades de entender o texto, busque desenvolver seu próprio percurso de compreensão e torne-se um leitor proficiente.

A partir dessas considerações e tomando como contexto de estudo um momento de formação de professores, desenvolvemos algumas reflexões que apresentamos neste estudo. No final do primeiro trimestre de 2018, foi realizado um momento de formação docente em uma escola municipal de Ensino Fundamental no interior do Rio Grande do Sul. Para esse momento, a escola havia solicitado a oficina "Um click na leitura"s, que é ministrada por uma professora do Programa de Pós-Graduação em Ensino e do curso de Licenciatura em Letras de uma Instituição Superior de Ensino.

A oficina tem como temática principal apresentar aos professores um ensino de leitura que tem como objetivo o desenvolvimento da compreensão leitora. Já que o tempo disponibilizado para o momento era de apenas duas horas, as habilidades mais enfatizadas foram predição e inferenciação.

Como alguns dos professores se mostraram surpresos em relação às questões abordadas, formulamos um questionário com o objetivo de compreender como alguns professores dessa escola da rede municipal de Ensino Fundamental do interior do Rio Grande do Sul têm pensado o ensino da leitura e quais suas contribuições para a formação de leitores competentes e autônomos, nas diferentes áreas do conhecimento.

No presente texto, apresentamos algumas reflexões a partir das respostas dadas, relacionando-as a algumas lacunas na própria formação dos professores. Para estruturar o texto, organizamos os tópicos do seguinte modo: num primeiro momento, apresentamos o referencial teórico que embasa nossas reflexões e, em seguida, apresentamos as respostas dos professores e as análises realizadas.

5. A oficina em questão integra parte das ações de dois projetos de pesquisa com foco no ensino da compreensão leitora. Ambos os projetos são financiados pela Fundação de Amparo à Pesquisa do Estado do Rio Grande do Sul (FAPERGS). 
Ensinar a ler em diferentes áreas do conhecimento: o que pensam os professores...

\section{APRENDER E ENSINAR A LER}

A aprendizagem da leitura é um processo complexo que pode ser compreendido assumindo-se diferentes pressupostos epistemológicos. Entretanto, independentemente dos fundamentos teóricos, a leitura é reconhecida por seu papel essencial dentro do contexto sociocultural.

Numa perspectiva social, Carneiro (2003, p. 134) afirma que "quem lê entende melhor a sua cultura, a sua história" e, além disso, pode obter destaque no ambiente profissional, tornando-se capaz de "compreender os múltiplos códigos que se apresentam: sociais, culturais, linguísticos e outros", assegurando ao indivíduo a consciência dos valores da sociedade em que vive.

De acordo com Oliveira e Silveira (2014), a leitura é fundamental para que se desenvolva o senso crítico, permitindo que o leitor questione e colabore com o desenvolvimento de determinados assuntos, aprimorando, inclusive, a capacidade de opinar sobre eles. Isso resulta em uma fonte de diversas experiências, que são fundamentais para a "construção e domínio do conhecimento do indivíduo ampliando sua visão e os horizontes na vida cotidiana” (OLIVEIRA; SILVEIRA, 2014, p. 81).

Mas, para que a leitura se concretize em toda sua amplitude, é preciso reconhecer que não lemos do mesmo modo todos os textos com os quais interagimos. A respeito dessa questão, Solé (1998) argumenta que, considerando a diversidade de estruturas textuais, cada leitura se configurará uma construção de sentidos diferente.

Não encontramos a mesma coisa em um conto que em um livro de texto, em um relatório de pesquisa que em um romance policial, em uma enciclopédia que em um jornal. $\mathrm{O}$ conteúdo muda, naturalmente, mas não se trata apenas disto. As diferentes estruturas do texto impõem restrições à forma em que se organiza a informação escrita, o que obriga a conhecê-las, mesmo que intuitivamente, para se compreender esta informação de forma adequada (SOLÉ, 1998).

Dessa forma, entendemos que a aprendizagem da leitura requer o desenvolvimento de habilidades para que o estudante consiga tornar-se um leitor competente e, assim, transformá-la em um ato social de produção de sentido e formação de pensamento crítico.

Destacamos, dentre diversas habilidades que constituem o processo de compreensão leitora, a aprendizagem da inferenciação. Segundo Coscarelli (2002), 
consideram-se inferências "aquelas informações que o leitor adiciona ao texto". Sendo assim, trata-se de um processo fundamental para quem quer entender o caminho para a compreensão. No mesmo percurso, Pereira (2009) conclui que aprender a inferir é buscar apoio para a compreensão do texto no que constitui a língua - a fonética e fonologia, morfologia, sintaxe, semântica e pragmática. Isto é, entender que essas relações provocam o sentido do texto.

Considerando os pressupostos teóricos que norteiam nosso estudo, e em conformidade com Souza (2015), entendemos que a escola deve superar algumas concepções sobre o aprendizado da leitura e pensá-la como objeto de ensino. Concepções que se restringem ao entendimento da leitura como fruição ou como ato de decodificação têm formado leitores capazes de decodificar palavras, mas não de compreender o que leem (SOUZA, 2015, p. 276).

Dessa limitada visão de leitura resultam os fracos desempenhos de nossos estudantes em provas internacionais de avaliação da compreensão leitora, tais como a Prova PISA. Nessa prova, os alunos brasileiros não conseguem produzir inferências, comparações e contrastes, levantar hipóteses sobre o texto, produzir relações de intertextualidade e, consequentemente, não conseguem demonstrar a compreensão total dos textos (BRASIL, 2016, p. 102).

Tendo em vista a necessidade de repensar práticas de ensino, direcionamos também nosso olhar para o processo de formação docente, justamente porque, em nosso entender, a ausência de uma formação de professores voltada ao ensino da compreensão leitora compromete o desenvolvimento de habilidades de leitura nos alunos da educação básica, que, por sua vez, precisam saber ler com competência textos de diferentes áreas do conhecimento.

Nesse sentido, a partir de estudos sobre o Projeto Pedagógico Curricular (PPC) e as Matrizes Curriculares de algumas universidades, Gatti (2010) nos relembra que no contexto histórico dos cursos de licenciatura sempre esteve presente a "separação formativa" entre a formação de professor de educação infantil e anos iniciais do ensino fundamental e professor "especialista de disciplina" (GATTI, 2010, p. 1358).

A autora chama a atenção para as matrizes curriculares dos cursos de Pedagogia e outras licenciaturas. $\mathrm{O}$ estudo aponta que os componentes curriculares destinados a reflexões sobre os conteúdos a serem ensinados nas séries iniciais correspondem a apenas 7,5\% do currículo. Para a autora, esse dado revela que "conteúdos específicos das disciplinas a serem ministradas em sala de aula não são objeto dos cursos de formação inicial do professor" (GATTI, 2010, p. 1368). 
Ensinar a ler em diferentes áreas do conhecimento: o que pensam os professores...

No caso das demais licenciaturas, como Letras, Matemática, História e Ciências Biológicas, por exemplo, a autora observou que "não há uma articulação entre as disciplinas de formação específica (conteúdos da área disciplinar) e a formação pedagógica (conteúdos para a docência)" e, nem mesmo, um "núcleo compartilhado de disciplinas da área de formação para a docência”. Em outras palavras, não há articulação entre estudos sobre os aspectos pedagógicos e estudos sobre o campo teórico da formação de cada área do conhecimento (GATTI, 2010, p. 1373-1374).

Isso revela, entre outras questões, que o ensino da leitura e seus desdobramentos ainda é tema pouco abordado na formação de professores, muito embora as dificuldades de compreensão leitora de nossos alunos sejam evidentes em todas as áreas de conhecimento.

\section{O QUE PENSAM OS PROFESSORES SOBRE O ENSINO DA LEITURA}

\subsection{Procedimentos metodológicos}

Em abril de 2018, como dito anteriormente, foi realizado um momento de formação para professores de uma escola municipal de Ensino Fundamental no interior do Rio Grande do Sul. Como tema, foram abordadas algumas concepções de leitura (ler por prazer, letramento, leitura de mundo, compreensão) e enfatizados aspectos do processamento da leitura, para o ensino e desenvolvimento da compreensão leitora, com destaque para as estratégias de predição e inferenciação em diferentes áreas do conhecimento.

Considerando a importância do tema e a reação dos professores à abordagem, elaboramos um questionário para ser respondido pelos participantes do encontro. A partir da análise desse material, objetivamos compreender como esses educadores têm pensado o ensino da leitura e quais suas contribuições para que os alunos desenvolvam habilidades de compreensão leitora. Nesse questionário, os professores deveriam responder a) de que forma contribuem para o desenvolvimento da compreensão leitora; b) qual a importância do ensino da inferência e; c) se suas concepções a respeito do ensino da leitura se modificaram a partir da formação.

Participaram dessa pesquisa, de abordagem qualitativa, oito professores de Ensino Fundamental das áreas de Linguagens, Matemática, Humanidades e Anos Iniciais, os quais possuem experiência entre 18 e 36 anos de magistério. Por questões éticas e com o intuito de preservar as identidades dos sujeitos pesquisados, 
ao longo do artigo os respondentes foram denominados de Professor 1 ( $\left.\mathrm{P}_{1}\right)$, Professor $2\left(\mathrm{P}_{2}\right)$, e assim sucessivamente.

\subsection{ANÁlise E Discussão}

Dos oito questionários, utilizamos em nossa análise apenas seis, uma vez que dois dos participantes responderam a todas as perguntas em uma só resposta. A análise dos dados coletados foi realizada em aproximação à Análise de Conteúdo (BARDIN, 2012), a partir da qual emergiram três categorias que serão apresentadas na sequência: a) por que ensinar a inferir?; b) o que fazem para ensinar a compreender? e c) o que aprenderam?

\subsubsection{Por QUe ENSINAR A INFERIR?}

Como já mencionado, um dos temas tratados na formação foi a produção de inferências e, tendo em vista a importância do desenvolvimento dessa habilidade, perguntamos aos professores "por que é importante ensinar os alunos a inferir?".

A partir da análise das respostas, verificamos que, para os professores 1, 2, 3 e 6, a habilidade de inferir diz respeito ao desenvolvimento de capacidades complexas de raciocínio e de produção de sentido. Para eles, inferir está na esfera do pensamento complexo, como se vê nas seguintes expressões: "fazer pensar" ( $\left.\mathrm{P}_{2}\right)$, "concluir pelo raciocínio" e "acrescentar sentido" $\left(\mathrm{P}_{3}\right)$, "aprimorar as habilidades de interpretação" (P6) e "melhorar a compreensão da leitura" ( $\left.\mathrm{P}_{1}\right)$.

Parte-se do pressuposto, neste caso, de que inferir é condição para o desenvolvimento de habilidades de compreensão. Nesse sentido, Coscarelli (2002, p. 6) afirma que "todas as situações em que é preciso ler nas entrelinhas exigem a produção de inferências por parte do leitor da mensagem". Portanto, é responsabilidade do professor estimular o desenvolvimento da habilidade e, dessa forma, contribuir para que o aluno alcance sua competência leitora. Assumir a inferência como porta para o raciocínio, para o pensamento complexo, para compreensão e para a interpretação é ponto de partida apropriado, em nosso entender, para que a própria aprendizagem possa se consolidar.

Já o Professor 4 entende que a inferência resulta em "saber posicionar-se diante das situações expostas na leitura feita”. Essa noção de inferência diz respeito ao entendimento de que inferir é uma habilidade da esfera do posicionamento crítico. Conforme Pereira (2009), entretanto, a inferenciação atua também como suporte 
Ensinar a ler em diferentes áreas do conhecimento: o que pensam os professores...

para a realização da predição, que, por sua vez, é fundamental para a produção de novas inferências, que alcançam a compreensão. Disso resulta "um confronto entre o leitor, através de seus conhecimentos prévios, e o texto, através das pistas linguísticas deixadas pelo escritor em todos os planos do texto" (PEREIRA, 2009, p. 14), o que caracteriza a produção de sentido ao que se lê. Inferir, portanto, não influencia diretamente o posicionamento crítico, porque se concretiza antes dele. Em outras palavras, a produção de inferências por meio da leitura resulta na produção de sentidos que, se apropriadamente concretizados, podem, então, resultar em posicionamento crítico. Nesse ponto, concordamos com Coscarelli (1996) que, já na introdução do texto, argumenta que uma visão simplificada da leitura, sem reconhecer os diferentes processos e as especificidades de cada atividade, pode resultar em equívocos no ensino da compreensão. Para a autora, uma visão genérica da leitura, em que não se reconhecem as subdivisões do processo, implica dificuldades em desenvolver estratégias de leitura específicas, “[...] pois não seremos capazes de identificar onde está o problema de cada aluno” (COSCARELLI, 1996, p. 163).

Por fim, o Professor 5 apresentou um conjunto de atividades que, em seu entender, podem desenvolver capacidades de inferenciação:

PROFESSOR 5: O incentivo à leitura, a busca por novos conhecimentos, aguçar a curiosidade, instigar a pesquisa... São formas de auxiliar nossas crianças para o aprimoramento das habilidades de compreensão, interpretação, entre outras. Apresentar um livro ou texto e permitir que a criança fale sobre o mesmo (suas ideias, quais as expectativas, o que será que esse quer dizer...) faz com que ela sinta desejo em verificar se as suas primeiras impressões irão ou não se concretizar após a leitura. Acredito que esse momento torna-se muito significativo e prazeroso.

Figura 1: Resposta dada pelo Professor 5 à pergunta "Por que é importante ensinar os alunos a inferir?" - Fonte: elaborado pelas autoras.

Considerando a resposta do Professor 5, concordamos com Coscarelli (1996), para quem propostas que desenvolvam a leitura como um todo não têm necessariamente o efeito esperado. Assim como pensa a autora, parece-nos mais apropriado ter, num primeiro momento, clareza das diferentes estratégias de leitura envolvidas no processo de produção da compreensão, para que se desenvolvam atividades específicas a cada uma das partes, sem, no entanto, deixar de considerar a leitura como um todo. 
O Professor 5 tem uma visão apropriada de uma etapa da produção da compreensão: a predição, mas não soube relacioná-la à inferência, tema da pergunta do questionário. E, além disso, associa a leitura à fruição, ao prazer de ler. Como dissemos, ainda que esse entendimento de leitura seja muito importante, por si só não resolve o problema do déficit em compreensão leitora dos estudantes. Como apontam Pereira e Scliar-Cabral (2012, p. 16), o trabalho pedagógico desenvolvido em algumas salas de aula, no que se refere ao ensino da leitura, evidencia falta de definição teórica, ficando ao sabor das intuições e preferências dos professores. Para as autoras - e concordamos com elas -, as aulas de ensino da leitura podem ser muitas vezes interessantes e criativas, mas pouco eficientes para o alcance do aprendizado necessário.

\subsubsection{O QUE FAZEM PARA ENSINAR A COMPREENDER?}

Perguntamos aos professores de que forma avaliam sua contribuição para o desenvolvimento da leitura de seus alunos. As respostas apresentadas apontam para dois caminhos: um grupo de professores mencionou aspectos metodológicos do ensino da leitura, enquanto outro grupo indicou os diferentes gêneros textuais apresentados aos alunos em contextos de leitura.

No primeiro grupo, estão os professores 1, 2 e 4 . O professor 1, que trabalha as disciplinas de História e Geografia, considera o ensino da leitura com um grande desafio e diz que procura "[...] ler junto com os alunos, fazendo intervenções, questionando, estudar conceitos". Para o professor $2, \mathrm{do}_{3}{ }^{\circ}$ ano do EF, sua forma de contribuição para o ensino da leitura é "propondo diferentes situações de leitura e acompanhando este processo". Na área das Exatas, por sua vez, o professor 4, dos anos finais, diz que sua contribuição se dá "fazendo questionamento ao aluno e fazendo com que eles digam o que eles leram sem olhar o exercício (situações problemas)”.

Os professores desse grupo parecem entender que seu papel é mediar a interação do aluno com o texto. Ao fazer intervenções, questionar e acompanhar o processo, os professores demonstram estar atentos ao modo como seus alunos produzem os significados dos textos. Esse modo de atuar sobre o processamento da leitura deve resultar em qualificação da aprendizagem da inferenciação, desde que resulte efetivamente na produção de sentido do texto. Chamou-nos a atenção, inclusive, o fato de um dos professores mencionar que solicita que seus alunos sejam capazes de parafrasear o texto lido, o que revela preocupação com a aprendizagem da inferenciação. 
Ensinar a ler em diferentes áreas do conhecimento: o que pensam os professores...

No segundo grupo, estão os professores 3, 5 e 6. O professor de Linguagens do $7^{\circ}$ ano relatou que, na escola, leem “[... vários tipos textuais, como: livros (prosa), textos de crônicas, poesias, jornais, revistas, histórias em quadrinhos (que são produzidas também), leitura visual entre outros" (professor 3 ). O professor 5 , que atua com o $5^{\circ}$ ano, afirmou que "a leitura precisa estar presente no dia-dia da criança, assim como no planejamento do professor. Proporcionar situações diversas: cantinho/espaço para leituras, hora da novidade... Trocas. Incentivar a retirada de livros na biblioteca, fichas de leituras, seminário, estudo e pesquisa de escritores, autor presente, produção textual/digitação. Exploração de materiais diversos: jornais/ gibis/revistas.... No $2^{\circ}$ ano, o professor 6 relata que seu trabalho acontece com "produções textuais, leitura deleite, pesquisas, retiradas de livros da biblioteca da escola e pública, leitura diária na sala de aula, baú de tesouro (livros/cantinho da leitura na sala), explorar materiais diversos p/ leitura, leitura de mundo”.

É muito importante oportunizar diferentes situações de experimentação leitora. Como menciona Morais (2013), o nível de desenvolvimento de habilidades de compreensão leitora está diretamente relacionado ao grau de exposição a materiais escritos. Entretanto, ao mesmo tempo em que se oportuniza o contato com diferentes gêneros textuais e diferentes experiências de leitura, é preciso também ter clareza acerca do tipo de leitura que se realiza em cada contexto e, portanto, reconhecer que cada uma dessas situações implica escolhas pedagógicas distintas e, em consequência, a aprendizagem de diferentes estratégias de leitura. Em resumo, muito além de promover diferentes contextos de interação com o texto, é preciso que o professor tenha clareza das diferentes estratégias de leitura que são requeridas em cada um desses contextos.

\subsubsection{O QUE APRENDERAM?}

Quando perguntados se o momento de formação os fez (re)pensar o ensino da leitura, os professores apontaram a necessidade e a importância de continuar estudando e aperfeiçoando seus conhecimentos. O professor 5 afirmou que "[em] toda formação, estudo, trocas, sempre aprimoramos nossos saberes”. O professor 1 acredita que "sim, pois precisamos refletir a presença da escola na sociedade, trabalhando um currículo significativo, trazendo mudanças no ensino aprendizagem”.

O professor 7, que trabalha com os anos iniciais, relatou que "aprimoramos nossos saberes, através das trocas. $\mathrm{O}$ meu pensar modificou, sempre trabalhar para que o aluno 
adquira o prazer pela leitura (fruição)". Em nosso entender, entretanto, o ensino da leitura vai além do conceito de fruição, uma vez que o estudante necessita desenvolver diversas habilidades para alcançar um bom desempenho enquanto leitor proficiente.

Destacamos, também, as respostas dos professores 3 e 4, que mencionam uma das preocupações reveladas durante a oficina. $O$ professor $3 \mathrm{diz}(\mathrm{re})$ pensar o ensino da leitura, pois pôde "[...] refletir sobre o comentário de que 'o aluno de séries finais, que não lê fluente, não interpreta corretamente”, e o professor 4 relata "refletir sobre o interpretar e compreender".

Nesse sentido, acreditamos que trabalhar apenas gêneros textuais pelos quais os alunos demonstram interesse restringe o uso das habilidades de leitura, isto é, não há o desenvolvimento de novas habilidades e estratégias que um texto mais complexo requer. E assim, quando o aluno se depara com situações como a Prova Brasil, o desempenho em compreensão leitora é baixo.

Hoppe e Costa-Hübes (2013, p. 11) afirmam que o estudante, quando avaliado pela Prova Brasil, é influenciado diretamente por fatores externos, como a necessidade de marcar uma alternativa dentro do tempo disponibilizado para a realização da prova e os seus conhecimentos prévios sobre o assunto. Por esses fatores, as autoras acreditam que, nesse caso,

[...] a leitura não é tida apenas como prática de extração, haja vista que implica compreensão e conhecimentos prévios que são constituídos antes mesmo da leitura. Constatamos, assim, que a leitura é fruto da interação que permite ao leitor se posicionar ativamente diante do enunciado, construindo significados e produzindo sentidos para aquilo que lê (HOPPE; COSTA-HÜBES, 2013, p. 11).

Complementamos essas afirmações com Sousa e Hübner (2016), para quem a compreensão é um processo cognitivo amplo com ocorrência em diversos níveis de consciência e que depende, também, da memória e das relações que estabelecemos entre o novo e o velho. Sendo assim, "é um processo que perpassa muitas tarefas cotidianas, desde a comunicação oral, a leitura, a escrita, o cálculo, até o aprendizado de modo geral" (SOUSA; HÜBNER, 2016, p. 47).

Os professores $3 \mathrm{e} 4$ demonstram preocupação com a importância de se atentar para todas as variáveis envolvidas no processo de compreensão leitora.

Por fim, fazemos menção ao relato do professor 2: "a capacitação levou a um olhar ainda mais atento ao planejamento das situações propostas". Planejar novas 
Ensinar a ler em diferentes áreas do conhecimento: o que pensam os professores...

situações, criar novos contextos e auxiliar os alunos a desenvolverem suas próprias estratégias de leitura é fundamental na prática docente. Incentivar o gosto pela leitura é essencial, mas, anterior a isso, é necessário que o aluno saiba fazer uso das suas habilidades de leitura e compreenda bem o que lê.

Ao analisar as respostas, foi possível perceber que a fruição recebe grande foco na sala de aula, enquanto as estratégias para compreensão leitora ainda são trabalhadas de forma mais incipiente. Considerando a forma de ensino utilizada pelos professores entrevistados, evidenciamos a importância de se refletir sobre sua formação inicial e continuada, tendo em vista que fica evidente que o ensino da leitura e seus desdobramentos ainda não tem feito parte da atuação dos professores, mesmo que tenham demonstrado em suas respostas uma genuína preocupação com a qualidade da formação leitora de seus alunos.

\section{CONSIDERAÇões Finais}

A partir das respostas dos questionamentos feitos aos professores pudemos verificar, ainda que de maneira incipiente, o modo como eles trabalham a leitura com seus alunos. Ainda assim, evidenciamos que, além de saber quais gêneros textuais e quais ferramentas de leitura são utilizadas em sala de aula, seria necessário que tivessem também conhecimento da forma como se abordam os textos trabalhados e como podem auxiliar seus alunos no desenvolvimento de estratégias de leitura, além de apenas incentivá-los a ler por prazer.

Reafirmamos, a partir desse estudo, a importância da formação inicial e continuada dos professores, pois percebemos que o conceito de inferência, por exemplo, se mostrou novo e que ainda precisa ser mais compreendido, para que, de fato, venha a fazer parte do ensino da leitura em todas as áreas do conhecimento.

\section{REFERÊNCIAS}

BARDIN, L. Análise de conteúdo. São Paulo: Edições 70, 2012.

BRASIL. Ministério da Educação. Brasil no PISA 2015: análises e reflexões sobre o desempenho dos estudantes brasileiros. São Paulo: Fundação Santillana, 2016. Disponível em: <http://inep.gov. br/web/guest/pisa-no-brasil>. Acesso em: 27 mar. 2019.

CARNEIRO, H. M. S. Leitura e Inclusão social. Fortaleza: Revista de Letras, n. 25, v. 1/2, p. 132-135, 2003. Disponível em: <http://www.periodicos.ufc.br/revletras/article/view/2255/1725>. Acesso em: 20 nov. 2018. 
COSCARELLI, C. V. Reflexões sobre as inferências. In: VI CBLA - CONGRESSO BRASILEIRO DE LINGÜÍSTICA APLICADA, 2002, Faculdade de Letras da UFMG, Belo Horizonte. Anais... Belo Horizonte, MG. Disponível em: <http://ebooks.pucrs.br/edipucrs/anais/sial/2011/src/9. pdf $>$. Acesso em: 11 mar. 2019.

COSCARELLI, C. V. O ensino da leitura: uma perspectiva psicolinguística. Boletim da Associação Brasileira de Linguística. Maceió: Imprensa Universitária, dez. 1996. p. 163-174.

FERRAREZI Jr., C.; CARVALHO, R. S. de. De alunos a leitores: o ensino da leitura na educação básica. 1. ed. São Paulo: Parábola Editorial, 2017.

GATTI, B. A. Formação de professores no Brasil: características e problemas. Educação \& Sociedade, v. 31, n. 113, 2010, p. 1355-1379. Disponível em: <https://www.redalyc.org/html/873/87315816016/>. Acesso em: 26 mar. 2019.

HOPPE, M. C.; COSTA-HUBES, T. da C. Concepções de leitura na educação básica e sua relação com a Prova Brasil. In: XI JORNADA DO HISTEDBR, 2013, Cascavel. Anais... Cascavel, PR, 2013.

KATO, M. A. O aprendizado da leitura. 6. ed. São Paulo: Martins Fontes, 2007.

MORAIS, José. Criar leitores: para professores e educadores. Barueri: Minha Editora, 2013.

OLIVEIRA, A. G.; SILVEIRA, D. A importância da leitura na vida acadêmica e cotidiana. Infarma Ciências Farmacêuticas, 2014. Disponível em: <http://revistas.cff.org. $\mathrm{br} /$ ?journal=infarma\&page $=$ article\&op=view\&path\%5B ${ }_{55} \mathrm{D}=638 \&$ path\%5 $\mathrm{B} \% 5 \mathrm{D}=522>$.

Acesso em: 20 nov. 2018.

PEREIRA, V. W. Predição leitora e inferência. In: CAMPOS, J. (Org.). Inferências linguísticas nas interfaces. Porto Alegre: EDIPUCRS, p. 10-22, 2009. [E-book] Disponível em <http://www. pucrs.br/edipucrs/inferencias.pdf $>$. Acesso em: 23 nov. 2018.

PEREIRA, V. W.; SCLIAR-CABRAL, L. Compreensão de textos e consciência textual: caminhos para o ensino nos anos iniciais. Florianópolis: Insular, 2012.

SOLÉ, Isabel. Estratégias de Leitura. 6. ed., Porto Alegre: Artmed, 1998.

SOUSA, L. B; GABRIEL, R. Aquisição lexical através da leitura. Porto Alegre: EDIPUCRS, 2011. Disponível em: <http://ebooks.pucrs.br/edipucrs/anais/sial/2011/src/9.pdf>. Acesso em 23 nov. 2018.

SOUZA, M.J.R. A importância da leitura na prática docente. Revista labirinto, ano Xv, v. 23, p. 262-277, 2015.

\section{SOBRe AS AUTORAS}

Pâmela Lopes Vicari é acadêmica do curso de Letras - Licenciatura em Língua Portuguesa e Espanhola, pela Universidade do Vale do Taquari - UNIVATES. Atua como bolsista de iniciação científica na pesquisa Aprendizagem e ferramentas digitais no Ensino Superior, pela mesma instituição. Tem experiência em Linguística nas áreas de compreensão leitora e ensino da leitura. E-mail: pamela.vicari@univates.br. 
Ensinar a ler em diferentes áreas do conhecimento: o que pensam os professores...

Dayene Borges Guarienti é graduanda em Engenharia Civil pela Universidade do Vale do Taquari - Univates. Tem experiência na área de ensino e educação, com pesquisa nos seguintes temas: compreensão leitora, objetos digitais de aprendizagem, estratégias de leitura, metodologias ativas. É bolsista de iniciação científica, vinculada à Fundação de Amparo à Pesquisa do Estado do Rio Grande do Sul (FAPERGS).

E-mail: dayene.guarienti@univates.br.

Kári Lúcia Forneck possui graduação em Letras pelo Centro Universitário Univates (2002), especialização em Ensino de Língua Portuguesa pelo Centro Universitário Univates (2004), mestrado em Linguística e Letras pela Pontifícia Universidade Católica do Rio Grande do Sul (2006) e doutorado em Linguística (2016), também pela Pontifícia Universidade Católica do Rio Grande do Sul. Atualmente trabalha na Universidade do Vale do Taquari Univates, onde atua como docente do Curso de Letras e do PPG em Ensino e responde pela vice-direção do Centro de Ciências Humanas e Sociais (CCHS). Tem experiência em Linguística, atuando nos seguintes temas: processamento cognitivo da leitura, produção de inferências, compreensão leitora, ensino da leitura, processamento de metáforas e interdisciplinaridade entre Linguística e Neurociências.

E-mail: kari@univates.br.

Silvana Neumann Martins possui graduação em Letras - Licenciatura Plena - Habilitação em Português e Literaturas pela Faculdade de Educação Ciências e Letras do Alto Taquari (1987), Especialização e Ensino de Literatura (2001) e Especialização em Gestão Universitária (2007), Mestrado em Educação pela Pontifícia Universidade Católica do Rio Grande do Sul (2005) e Doutorado em Educação, também pela PUC-RS (2010). Atualmente é docente permanente na Universidade do Vale do Taquari - UNIVATES e, além disso, professora do Mestrado Profissional em Ensino de Ciências Exatas, do Mestrado em Ensino e do Doutorado em Ensino, da mesma IES. Tem experiência docente, com ênfase em Metodologias Ativas de ensino e de aprendizagem, Empreendedorismo, Metodologia do Ensino Superior, Produção Textual e Leitura, atuando principalmente nos seguintes temas: formação de professores, 
educação empreendedora, empreendedorismo, metodologias ativas, leitura e produção textual e gestão no ensino.

E-mail: smartins@univates.br.

Recebido em o1 de julho de 2019 e aprovado em 23 de setembro de 2019. 